\title{
LA PANDEMIA COVID-19 Y SU IMPACTO EN LA INDUSTRIA AUTOMOTRIZ MEXICANA, 2020
}

THE COVID-19 PANDEMIC AND ITS IMPACT ON THE MEXICAN AUTOMOTIVE INDUSTRY, 2020

Francisco Javier Aguilar García ${ }^{1}$ javier.aguilar@sociales.unam.mx

Alejandro Lira Moctezuma alejandroliramoctezuma@hotmail.com 
Para citar este artículo:

Aguilar García, F. J., \& Lira Moctezuma, A. (2020). La pandemia COVID-19 y su impacto en la industria automotriz mexicana, 2020. ESPACIO I+D, INNOVACIÓN MÁS DESARROLLO, 9(25). https://doi.org/10.31644/IMASD.25.2020.a04

\section{RESUMEN}

El presente artículo tiene como objetivo conocer el impacto que ha tenido la emergencia sanitaria de la Covid-19 en la industria automotriz en México, donde es una de las industrias más importantes. Ella representa un segmento significativo de la economía, de la cual dependen, de forma directa e indirecta, una masa importante de trabajadores, y que, ante este escenario excepcional, fue una de las primeras industrias que se vieron obligadas a suspender labores de manera inmediata. En ese sentido, dada su importancia, es de nuestro interés también conocer qué se hizo, por parte de las empresas, así como del gobierno federal, para afrontar este escenario de emergencia y si estas medidas han sido suficientes para mantener el habitual dinamismo de esta industria, así como para preservar la seguridad sanitaria y laboral de los trabajadores en distintas entidades del país durante la pandemia.

\section{Palabras Clave:}

Industria Automotriz, México, Pandemia Covid-19, Desempleo, Salud Pública, Políticas Públicas. 


\section{- Abstract-}

The objective of this article is to know the impact that the Covid-19 health emergency has had on the automotive industry in Mexico, which is one of the most important industries in the country that represents a significant segment of the economy, on which they depend, directly and indirectly, a significant mass of workers, and that, in this exceptional scenario, it was one of the first industries that paradoxically were forced to suspend work immediately. In this sense, given its importance, it is also in our interest to know what was done by the companies as well as by the government authorities to face this emergency scenario and if these measures have been sufficient to maintain, as far as possible, in habitual dynamism to this important industry, as well as to preserve the health and labor security of its workers in different entities of the country during the first quarters of the pandemic.

\section{Keywords:}

Automotive Industry, Mexico, Covid-19 pandemic, unemployment, public health, Publics Politics 
U

no de los sectores económicos del país que se ha visto duramente golpeado por la emergencia desatada por la pandemia de la Covid- I 9 a nivel mundial, ha sido la industria automotriz. Esta industria se divide en dos sectores: el sector terminal (en la que se realiza el diseño, desarrollo y manufactura de automóviles ligeros y pesados por parte de las grandes ensambladoras multinacionales) y de autopartes (que se compone por las empresas proveedoras de refacciones mecánicas de las primeras, las cuales están clasificadas en diferentes niveles).

Actualmente, México es el tercer país con la mayor exportación de vehículos y el cuarto en cuanto a exportación de partes y accesorios de vehículos a nivel mundial. Esta industria representa anualmente el $16 \%$ del PIB manufacturero y $3.6 \%$ del PIB nacional, de la cual se benefician varias entidades del país. Hasta el año 2019, ingresaban a México, según la Secretaría de Economía, 4.8 millones de dólares de Inversión Extranjera Directa (IED) destinados a la producción de vehículos, empleando al I.8\% de la población económicamente activa (PEA), lo que representa alrededor de 978 mil personas en todo el país, según el INEGI.

Asimismo, es un sector dinámico, debido a que tiene un impacto en 90 actividades económicas del sector secundario y 70 del sector terciario (INEGI, 20I8) y de la que dependen 3.6 millones de personas en su conjunto (Clúster Industrial, 2020a).

Es por ello que resultó paradójico que esta actividad fuera considerada, en un principio, como una actividad no esencial, viéndose en la obligación de suspender sus operaciones durante abril y mayo, poniendo en riesgo el sustento de una importante cantidad de trabajadores. Ahora que esta industria se ha reactivado, es menester preguntarse iqué hizo el gobierno durante ese periodo de tiempo?

Uno de los mecanismos básicos que posee el gobierno para injerir en este tipo de escenarios en los que se genera una enorme tensión social, son las políticas públicas. Sin embargo, el gobierno no implementó políticas específicas para esta industria central, con el objeto de mitigar los efectos económicos de la pandemia, sino, más bien, medidas únicamente de carácter sanitarias.

Por lo anterior, consideramos que las medidas implementadas por el gobierno, no fueron suficientes para proteger a la industria automotriz y a sus trabajadores, durante el primer bimestre de la pandemia, que es cuando comenzaron a ser evidentes los efectos económicos y sociales de la pandemia.

Para ello, trazaremos el impacto que ha tenido la pandemia del coronavirus en la industria automotriz nacional; posteriormente, conoceremos las medidas del gobierno federal para esta industria. Enseguida, abordaremos el impacto que tuvieron en tres importantes entidades federativas como Puebla,Aguascalientes y Guanajuato, que tienen una destacada participación en la producción de autopartes y vehículos. 
Si bien la emergencia sanitaria no ha concluido, se pueden trazar sus rasgos económicos y de salud, así como presentar conclusiones preliminares al respecto.

\section{EL IMPACTO DE LA PANDEMIA EN LA INDUSTRIA AUTOMOTRIZ MUNDIAL}

Los principales países productores de automóviles en el mundo son 10 : China, Estados Unidos, Japón, Alemania, India, México, Corea de Sur, Brasil, España y Francia; los cuales se encargan, de manera conjunta, de fabricar aproximadamente el $77.7 \%$ del total de los vehículos que se usan en el mundo.

La empresa alemana Volkswagen tiene una participación en el mercado de más de 10 millones de unidades a nivel mundial, seguido de Toyota, Nissan, Peugeot, General Motors, Hyundai, Ford y Honda (Industria Nacional de Autopartes, 2019:5).

No obstante, ante la contingencia sanitaria por el coronavirus, la industria automovilística fue duramente sacudida por un marcado efecto dominó, debido a la enorme dependencia (desigual) que existe entre estos países, en las diferentes fases del proceso de producción. En este sentido, "más del 80 por ciento de la cadena de suministro de automóviles del mundo está conectada a China" (Cit. por la Cámara de Industria y Comercio Argentino-Alemana, 2020), por lo que el cierre del mercado de componentes automotrices chinos, cuyas plantas de producción se ubican en la ciudad de Wuhan, el epicentro del virus perturbó a toda la industria.

Esto se agravó todavía más cuando la epidemia se convirtió en pandemia y los países que figuran en esta importante industria se vieron afectados en cuanto al número de contagios por la Covid-19, durante el primer semestre de la expansión del virus, viéndose obligados, en distintos tiempos, a suspender parcial o totalmente muchos de los complejos industriales para cumplir con las reglamentaciones sanitarias.

Así, Alemania, uno de los principales socios del gigante asiático, anunciaría a finales de marzo la suspensión temporal de la producción de Volkswagen y Mercedes-Benz por falta de suministros mecánicos y por el necesario confinamiento, lo cual afectó también a la industria brasileña, que se vio obligada a interrumpir la producción de autopartes. De manera simultánea, prácticamente todos los complejos automotrices de Estados Unidos entraron en paro técnico (Cantera, 2020). Sin embargo, a pesar de que este país reactivó su industria automotriz escalonadamente el II de mayo, no sería lo mismo en tanto que México se mantuviera en cuarentena, a razón de que las plantas estadounidenses requieren de la manufactura mexicana, así como de la canadiense, para concluir sus productos.

En Corea del Sur también se cerrarían las plantas de Hyunday por segunda ocasión, desde febrero, debido al rebrote de la pandemia y al 
desabasto de repuestos. "Otras empresas japonesas, como Nissan, Honda o Isuzu, también se vieron obligadas a suspender temporalmente su producción, o a reducirla, debido a las interrupciones en el suministro de autopartes, dado que desde China les ingresan el 30\% de los repuestos" (Infobae, 2020).

El grupo italo-estadounidense, Fiat-Chrysler Automobiles, detuvieron sus líneas de ensamble en Serbia, así como en Italia, debido a la extensión de la cuarentena, tras alcanzar en aquel momento, más de 800 fallecimientos (Infobae, 2020). Mientras que, en España, "Seat, la filial española del Grupo Volkswagen, analizaba enviar el personal de la planta en Barcelona a sus casas, debido a problemas con los suministros de autopartes" (Infobae, 2020). En ese entonces, el país ibérico tenía más de 9 mil infectados, el máximo registrado hasta ese momento en el viejo continente. Por su parte, la empresa francesa Renault, cuyas fábricas están repartidas en 16 países en todo el mundo, anunció su salida de China, corroborando el riesgo de quebrar por falta de apoyo (Forbes, 2020) y por la decisión de su socio Nissan de abandonar Europa.

Esta situación, que deterioró la cadena de valor a escala global, no solo mermó la dinámica de tan importante sector económico de cada país, sino, además, produjo una serie de despidos masivos, dejando sin ingresos a una enorme cantidad de trabajadores en todo el mundo, en medio de la emergencia sanitaria.

Hasta ese momento, en Alemania, según la Asociación Europea de Fabricantes de Automóviles (ACEA), más de 500 mil trabajadores dejaron de laborar en alguna de las fábricas automotrices del país germano; en Francia fueron un total de 90 mil empleos perdidos; por su parte, en Italia no se logró mantener a más de 69 mil trabajadores en las líneas de ensamble; mientras que 60 mil españoles no volverán a su lugar de trabajo (Portal automotriz, 2020). Estos se sumaron, según el portal Télam (2020), a los más de II millones de desempleados en la eurozona, registrados únicamente en el mes de abril, cuya tasa de desempleo subió a $7.3 \%$, con respecto al $5 \%$ del mes anterior.

Mientras que, en Estados Unidos, según DW (2020), entre el mes de marzo y abril, periodo en el que suspendieron actividades en este sector, la tasa de desempleo pasó de $4.4 \%$ a $14 \%$, el índice más alto registrado en la historia estadounidense.

\section{EL IMPACTO DE LA PANDEMIA EN LA INDUSTRIA AUTOMOTRIZ EN MÉXICO}

En cuanto a México, las cosas no fueron distintas. Debido al desabasto de refacciones y a la pandemia, las grandes empresas automotrices que tienen sus ensambladoras en diferentes partes del territorio nacional, 
suspendieron actividades escalonadamente a partir del 23 de marzo con la implementación de la llamada Jornada de Sana Distancia (que consistió en la suspensión de varias actividades sociales, económicas y recreativas consideradas como no esenciales hasta el 20 de abril); en aquel momento se contabilizaban un poco más de 310 infectados y 2 decesos a nivel nacional por coronavirus.

Sin embargo, suspender esta industria resultaba un escenario complejo por dos aspectos: I) la actividad de este sector beneficia a II entidades: Aguascalientes, Puebla, Guanajuato, Nuevo León, San Luis Potosí, Sonora, Estado de México, Jalisco, Morelos, Coahuila y Baja California; en donde, de manera conjunta, operan alrededor de 24 plantas, empleando - hasta antes de la pandemia, según el INEGI- a 965 mil trabajadores; de dicha cifra, más de 800 mil corresponden a la fabricación de autopartes (Asociación Mexicana de Distribuidores de Automotores, 2017:10); siendo uno de los principales sectores económicos generadores de empleo. No obstante, si bien no se podía dejar a esta enorme cantidad de trabajadores sin ingreso, no es menos cierto que 2) no se podía poner en riesgo la salud de los mismos.

Finalmente, las principales empresas automotrices que cuentan con una importante presencia en México, como Nissan, General Motors, Volkswagen, Toyota, Kia y Honda, que concentran el $74 \%$ del mercado de vehículos ligeros en el país (Mendoza, 2019), tuvieron que tomar diferentes medidas que restringieron sustancialmente sus operaciones, como el paro técnico de dos semanas llevada a cabo por Honda, Toyota, Audi, FCA, Ford y la General Motors. Además de que las plantas armadoras de cada una de estas empresas tuvieron que ser sometidas a "las medidas de contingencia como limpieza y sanitización a profundidad [...] para evitar contagios de la COVID-19"' (Clúster Industrial, 2020b), y, así, volver lo más pronto posible a sus actividades.

No obstante, la reactivación general de esta industria se prolongó hasta el I de junio ( 10 semanas después de lo previsto, cuando las autoridades federales y locales la consideraron como actividad esencial), debido al alarmante escenario al que había evolucionado la pandemia en el país, que registró un incremento de más de $1 \mathrm{I} 2$ mil nuevos infectados y más de 15 mil fallecidos por coronavirus entre principios de abril y finales de mayo.

En consecuencia, durante marzo y mayo, los números de la industria eran previsiblemente negativos. Según los reportes mensuales del INEGI (2020a), la producción mexicana de autos a nivel nacional cayó un 91.5\%, cuyo punto más bajo fue de marzo a abril produciéndose 3,722 unidades (gracias a KIA que no detuvo sus operaciones), (Véase Gráficol); mientras que en el mercado interno las ventas se redujeron $60 \%$ en este mismo periodo, elevándose en mayo un 20\% (Véase Gráfico 2). 


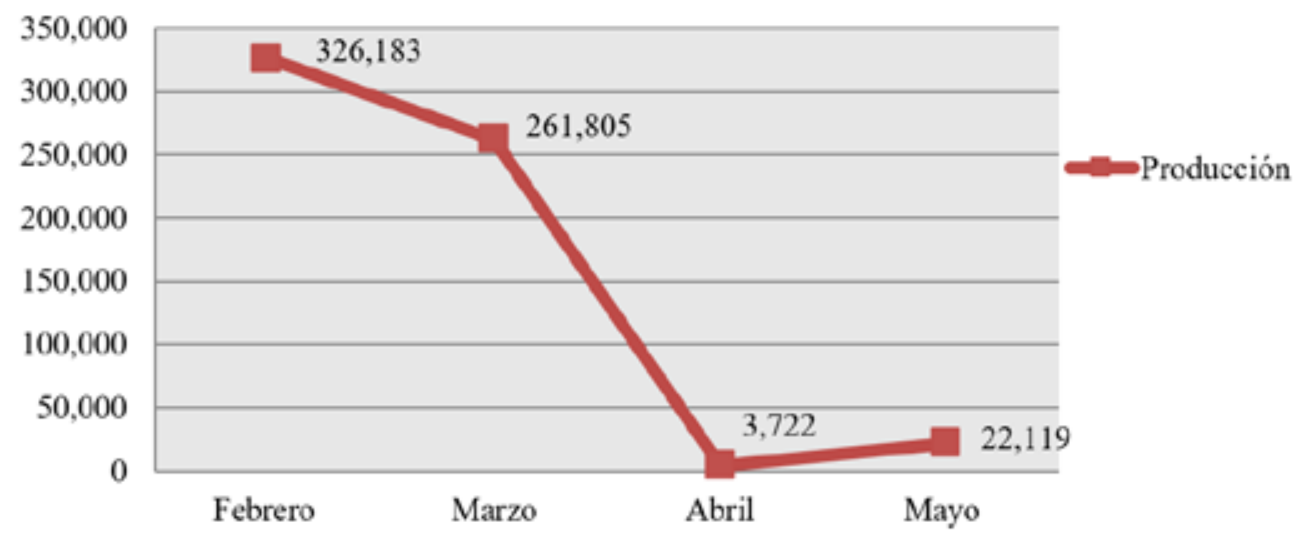

Gráfico 1. México. Producción de automoviles (Unidades), 2020. Fuente: elaboración propia con datos del INEGI

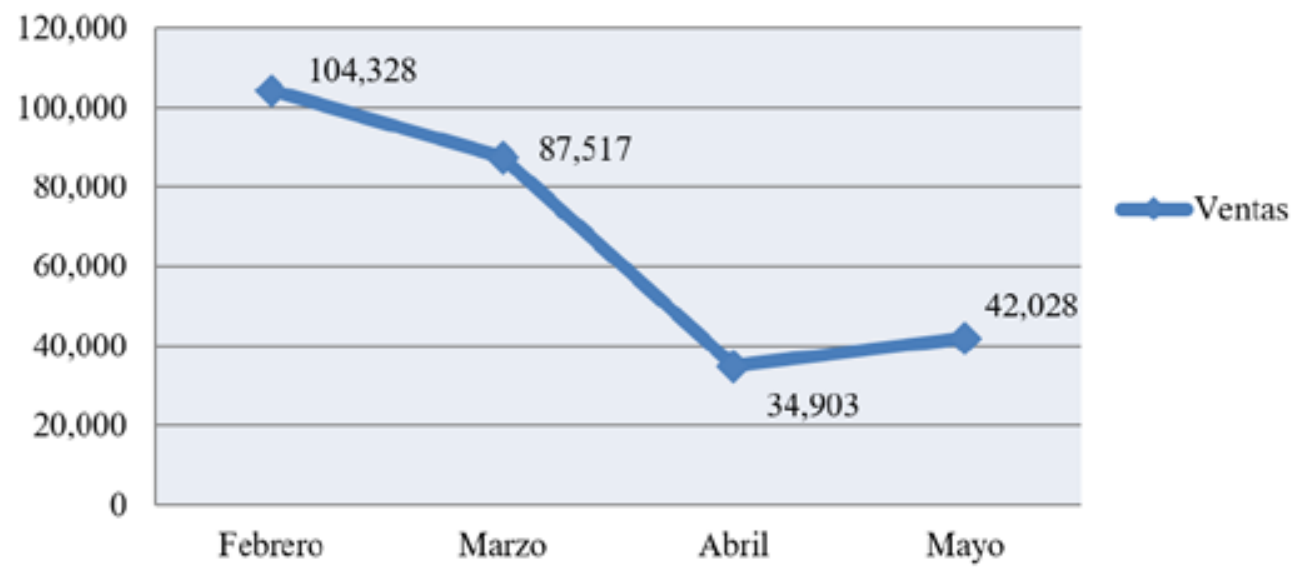

Gráfico 2. México. Ventas de automólives (Unidades), 2020. Fuente: elaboración propia con datos del INEGI

Por otro lado, debido a esta suspensión de actividades, la exportación mexicana de automóviles se redujo $90.2 \%$ en los meses de marzo-abril; para el mes de mayo la reducción fue de $45.9 \%$ (Véase Gráfico 3), por lo que Estados Unidos (que es el principal destino de los autos producidos en México), importó más vehículos provenientes de Japón y Corea de Sur durante este último mes. 


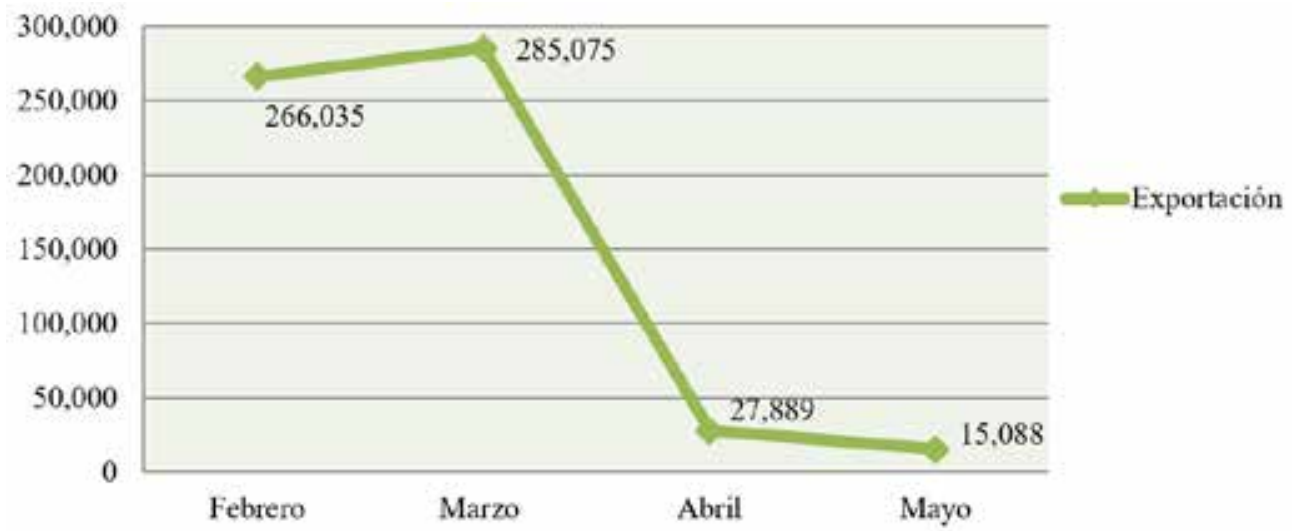

Gráfico 3. México. Exportación de automóviles (Unidades), 2020. Fuente: elaboración propia con datos del INEGI

En cuento al desempleo, durante el mes de abril, según datos del INEGI,“la industria automotriz recortó 24 mil 7I I plazas laborales [a nivel nacional], una reducción de 2.6 por ciento en la plantilla laboral, en comparación con lo registrado un mes antes. Se trata de la mayor reducción que reporta el sector para un mes desde que se tiene registro" (Sánchez, 2020a).

Mientras tanto, la Red de Clúster Automotrices de México pronosticaba que serían alrededor de 196 mil puestos laborales perdidos en los siguientes meses (Juárez y López, 2020). Por su parte, la Confederación de Cámaras Industriales (Concamin), señaló que, tras la caída de la demanda de vehículos por parte de Estados Unidos, la cantidad de empleos que podrían estar verdaderamente en riesgo constituyeron 800 mil (Rodríguez, 2020).

\section{MEDIDAS GUBERNAMENTALES PARA LA INDUSTRIA AUTOMOTRIZ MEXICANA FRENTE A LA PANDEMIA DEL CORONAVIRUS}

Durante la semana en la que la industria automotriz suspendió sus actividades de forma temporal, la Asociación Mexicana de la Industria Automotriz, A.C, (AMIA), así como la Asociación Nacional de Productores de Autobuses y Tractocamiones (ANPAT), la Asociación Mexicana de Distribuidores de Automotores (AMDA) y la Industria Nacional de Autopartes (INA), enviaron una serie de propuestas al gobierno federal mediante las cuales este sector industrial podría hacer frente, a corto y largo plazo, a la emergencia sanitaria, entre las cuales destacaban: I) reconocer la actividad industrial automotriz como esencial, y como tal, 2) no limitarla con medidas restrictivas para su operaciones; 3 ) postergar la entrada en vigor de T-MEC hasta el I de enero del 202I; 4) subvenciones para las empresas proveedoras de autopartes; 5 ) un programa de protección al empleo para mantener la planta laboral con un subsidio al ingreso de los trabajadores y créditos fiscales equivalente al $50 \%$ del salario, así como 
otorgar becas a aquellos trabajadores que se vean afectados por el recorte de personal hasta que la empresa retome sus productividad promedio; 6) suspensión del pago de Impuesto Sobre la Renta (ISR); 7) acelerar la devolución de impuestos al IVA; 8) deducción de prestaciones laborales; 9) incrementar la deducibilidad del Impuesto Sobre la Renta en la adquisición de vehículos; 10) renovación de la flota vehicular y otorgamiento de créditos a pequeñas y medianas empresas.

El gobierno Federal y los estatales no recogieron sus propuestas. La única propuesta que tuvo resonancia en las autoridades gubernamentales fue considerar a este sector económico como una actividad esencial, por parte del Consejo de Salubridad General, a mediados de mayo; ello significó que tendría la autorización gubernamental para dar por concluida la suspensión y retomar sus operaciones a partir del I de junio, aunque con restricciones.

En realidad, el gobierno federal, con su política de no endeudamiento, durante este periodo no propuso o realizó ninguna política o serie de políticas públicas o incentivos económicos para este sector y sus distintos componentes, más que recomendaciones para salvaguardar la salud de los trabajadores. La política propuesta para la industria automotriz se aplicó igualmente a todas las demás industrias.

Las únicas medidas con que contaba la industria automotriz ante el declive de su actividad, seguirían siendo las medidas sanitarias que se habían implementado desde el inicio de la pandemia en todo el país en general (como el uso de cubrebocas, el gel antibacterial y la sana distancia), las cuales, según la Secretaría del Trabajo y Previsión Social (2020), eran llevadas a cabo, principalmente, por la General Motors, FCA México, Volkswagen, Se Bordnetze y Faurecia. Una vez que dio inicio la llamada nueva normalidad, estas medidas se incrementaron.

Esta nueva fase de la cuarentena, que se implementó teniendo como fondo un registro de 90 mil 664 infectados y 9 mil 390 fallecimientos en todo el país, y en el que se registró el nivel máximo de incremento de contagios en una semana, precisaba a las empresas automotrices llevar a cabo la reapertura de sus actividades de forma gradual y sin operar a toda su capacidad.

Asimismo, de forma interna, las empresas debían establecer, conforme a los Lineamientos Técnicos para la Reapertura de las Actividades Económicas, establecidos por parte de la Secretaría de Salud (2020), publicados en el Diario Oficial de la Federación el 29 de mayo, los protocolos de seguridad para prevenir el contagio de la Covid-19 de sus trabajadores en el interior de sus instalaciones, las cuales consistieron, principalmente, en: 
I) La toma de temperatura al momento de entrar a las instalaciones,

2) el lavado de manos constantemente,

3) el uso obligatorio del cubrebocas,

4) la reubicación interna de las zonas laborales para conservar la sana distancia entre trabajadores o, en su defecto, dotar de un Equipo de Protección Personal (EPP) a los mismos,

5) la colocación de barreras físicas en las estaciones de trabajo, comedores, etc.,

6) el incremento de la frecuencia del transporte y alternar asientos,

7) la desinfección de los espacios de trabajo,

8) la instalación de cercos sanitarios para atender aquellos obreros que presente algún síntoma y para la realización de la prueba Covid antes de ingresar a las instalaciones;

9) trabajo en casa del personal más vulnerable,

10) establecer escalonamientos y flexibilización de horarios y turnos y

II) filtros de ingreso y egreso del personal.

Por otro lado, se ha considerado como una medida indirecta del gobierno federal, el no haber declarado la contingencia sanitaria, sino la emergencia sanitaria, para intentar proteger a los trabajadores; este uso distinto de los términos hizo improcedente la aplicación del artículo 427, fracción VII de la Ley Federal del Trabajo, la cual considera como uno de los motivos de fuerza mayor para la suspensión de labores los casos de contingencia sanitaria, lo que le permitiría a las empresas realizar despidos injustificados después de pagarles una indemnización de un día de salario mínimo durante un mes a sus trabajadores; por lo que, en tanto no se declare como contingencia, las empresas están obligadas, por el contrario, a no rescindir la relación con sus empleados y deben continuar pagándoles su salario completo durante el tiempo que dure la cuarentena.

Con esta definición de emergencia sanitaria, el gobierno federal trasladó a las empresas, gran parte del costo económico de la pandemia, mientras el gobierno mismo no asumió una política económica más activa, para los diferentes tipos de empresas, pero sobre todo para las pequeñas y medianas, que no tuvieron recursos para sobrellevar los costos económicos y sociales.

\section{EL IMPACTO DE LA PANDEMIA EN LA INDUSTRIA AUTOMOTRIZ EN PUEBLA, AGUASCALIENTES Y GUANAJUATO}

Ante este escenario, es importante conocer la situación particular de tres entidades del país que tienen una destacada actividad de la industria automotriz, como son los casos de Puebla, Aguascalientes y Guanajuato, los cuales absorben de manera conjunta el 37\% de la Inversión Extranjera 
Directa (IED) para la fabricación de automóviles. Para su producción, estas empresas cuentan con grandes plantas ensambladoras, parte del objetivo de conocer el impacto de la emergencia sanitaria en esta industria, que ha carecido de políticas públicas de carácter económico. Aunque por otro lado, las grandes plantas han aplicado medidas sanitarias y han asumido la responsabilidad de retener a sus trabajadores. En el caso de las pequeñas y medianas empresas que están asociadas a la producción de autopartes y similares, no pudieron retener a los trabajadores.

\section{Puebla}

El Estado de Puebla es reconocido históricamente por su activa industria automotriz. encabezada por la empresa Volkswagen que, hasta finales del año pasado, era la tercera empresa con mayor producción y ventas vehiculares, con el $14.1 \%$ y el I I.I\% del país respectivamente. De esta empresa, junto con su subsidiaria Audi, dependen directamente alrededor de 12 mil empleos directos. Asimismo, existen en Puebla alrededor de 90 empresas de autopartes que suministran a Volswagen, a Ford y a General Motors, en su conjunto emplean a más de 90 mil trabajadores (Sánchez, 2020b). De esta manera, esta industria representa el $25 \%$ del PIB de la entidad.

Ante la emergencia sanitaria, la industria automotriz poblana fue la última en reincorporarse a la nueva normalidad, después de más dos meses y medio de mantener cerradas sus plantas. La razón de esto fue que el gobierno estatal, sin proponer alguna medida excepcional para esta industria, consideraba que, para finales de mayo, no contaba con las condiciones necesarias para reactivar este sector económico, debido al nivel de contagios que padecía la entidad que en aquel entonces: Puebla era el séptimo estado con mayor número de contagios de todo el país con más de 2 mil 800 casos y más de 300 fallecidos.

Así, mientras el resto de las ensambladoras en otros estados retomaban sus operaciones el I junio, aquellas que se localizan en Puebla lo hicieron hasta el 22 de junio. Lo cual no fue el caso de las empresas de autopartes de esta misma entidad, que se reactivaron escalonadamente durante la primera quincena de junio con el $30 \%$ de su plantilla laboral.

Durante el periodo de cuarentena, el fabricante Volkswagen redujo a cero su producción de vehículos ligeros; sus ventas en el mercado interno cayeron $67.3 \%$ y sus exportaciones bajaron un $96 \%$. En cuanto a su subsidiaria Audi, también dejó de producir automóviles ligeros a partir de la interrupción de las actividades; para mayo se lograron vender apenas 302 unidades, $48.3 \%$ menos que el mes de marzo. Mientras que sus exportaciones fueron ínfimas al enviar al mercado mundial únicamente $21 \mathrm{I}$ unidades que representaba una reducción de $\mathbf{9 8 . 6 \%}$ desde el fin del primer trimestre del año. 
Por lo que ambas armadoras, al no obtener ingresos, tomaron la decisión de recortar entre el 50 y $75 \%$ de su personal respectivamente (Hernández, 2020); en términos generales, desde el inicio del confinamiento obligatorio, fueron despedidos alrededor de 2 mil trabajadores de la industria automovilística del estado, mientras que otros 60 mil cobrarían la mitad de su sueldo durante el paro técnico (Morillón, 2020). Para mediados de mayo, se pronosticó que cerca de 18 mil empleos estaban en peligro de perderse a raíz del paro técnico (Melendéz, 2020).

Una vez que el gobierno estatal aprobó la reactivación de la actividad automotriz, Volkswagen volvería a operar en la nueva normalidad bajo la implementación de 130 protocolos y estrictas medidas de seguridad sanitarias para evitar el contagio entre sus trabajadores, y al $30 \%$ de su capacidad laboral. Asimismo, la armadora capacitó a todos sus trabajadores para reincorporarse a las actividades bajo los nuevos lineamientos de seguridad.

Entre los diferentes protocolos y medidas sanitarias destacan: I) varios filtros antes de entrar a las instalaciones, a través de los cuales se verificaba que el trabajador contara con los materiales de higiene (cubrebocas y gel antibacterial), así como la toma de la temperatura; 2) la separación física de las distintas áreas administrativas de la planta; 3 ) el monitoreo de los empleados para que sean acatadas las medidas sanitarias en toda la planta; 4) la entrega de los alimentos empaquetados y cerrados en la cafetería; 5) la colocación de mamparas de acrílico en cada mesa de trabajo; 6) la separación y señalamiento adecuado de cada área de trabajo para conservar la sana distancia y 7 ) el aumento del número de autobuses que transportan al personal desde sus casas hasta el centro de trabajo "para garantizar la sana distancia en los trayectos" (Zepeda, 2020).

No obstante, a finales de junio, la empresa alemana registró 70 trabajadores infectados por coronavirus; posteriormente, dicha cifra se elevó un poco más de 100 y contó al menos 10 fallecidos. Esto fue motivo suficiente para que el gobierno estatal insistiera nuevamente en la desactivación temporal de esta industria, aunque no se tenga la certeza de que los contagios se hayan dado dentro de las instalaciones, debido a que, para entonces, Puebla había experimentado, en un mes, un incremento del I $44 \%$ en cuanto al número acumulado de contagiados, para alcanzar la cifra de 9 mil 301 casos, con I mil I 32 decesos.

\section{Aguascalientes}

La industria automotriz aguascalentense gira, principalmente, en torno al fabricante japonés Nissan, que fue la segunda empresa con mayor producción de automóviles en el país con el $14.6 \%$ y el $20 \%$ de las ventas a finales del 2019 . Por lo que, tras cerrar temporalmente sus dos plantas, 84 empresas de 
autopartes, que emplean a 30 mil personas, dejaron de operar. En términos generales, el paro técnico ponía en riesgo un total de 180 mil empleos directos e indirectos, según el Sindicato de la Industria Automotriz y Metalúrgica (Ramos, 2020a). Esta actividad industrial representa 19\% del PIB estatal.

A diferencia del estado de Puebla, la entidad hidrocálida ha tenido un nivel relativamente bajo de contagios por coronavirus desde que inició la emergencia sanitaria, por lo que la industria automotriz, tras alistar una serie de protocolos sanitarios como única acción por parte del gobierno estatal, retomó paulatinamente sus operaciones a partir del 18 de mayo; para entonces contaba con 703 contagiados y 2l fallecidos.

Durante el paro técnico decretado por el gobierno federal, Nissan no produjo automóviles en el mes de abril; para cuando se reactivaron sus líneas de ensamblaje con el $30 \%$ de su capacidad, la producción alcanzó 2, I 24 unidades que es $95.4 \%$ menos en comparación con el mes de marzo. Asimismo, únicamente vendió un total de 8,752 unidades en territorio nacional que representaba $50 \%$ menos en el mismo periodo; en cuanto a la exportación, fueron enviadas al mercado mundial apenas 3,40 I unidades en mayo, $90.5 \%$ menos desde que inició el paro técnico.

Por su parte, el Instituto de Servicios de Salud del Estado de Aguascalientes (ISSEA), junto con la Secretaría de Desarrollo Económico (SEDEC) y la Secretaría General de Gobierno (Seggob), establecieron una serie de protocolos de sanidad para esta industria un mes después del cierre de las plantas, entre las que destacaban: I) el uso del tapete sanitario, 2) filtro sanitario, 3) un correcto abastecimiento de agua potable para las diferentes necesidades, 4) sanitización de la infraestructura y del equipamiento, 5) contar con una bitácora donde se registre la periodicidad del uso de limpieza y del personal que lo lleve a cabo, 6) el uso del cubrebocas, 7) mantenerse la sana distancia, 8) no usar reloj, joyas y/o accesorios en las manos y el uso del cabello corto o recogido por parte del personal de cocina, 9) contar con una unidad médica y 10) la sanitización del transporte para el traslado del personal a sus hogares, entre otras (Instituto de Servicios de Salud del Estado de Aguascalientes, 2020).

No obstante, a pesar de que la reactivación de las líneas de ensamble de Nissan se dio antes de lo proyectado por las autoridades federales, la empresa nipona no pudo evitar el recorte de su plantilla laboral para reorganizar sus finanzas. A principios de junio, se anunció que serían despedidos 200 trabajadores, sin embargo terminaron siendo 500, según la Federación de Trabajadores de Aguascalientes (FTA); 300 pertenecían a empresas proveedoras de Nissan (Ramos, 2020b).

En Junio se dio el inicio de la nueva normalidad, la entidad hidrocálida contaba un total de I,702 casos de contagios y 46 fallecidos; no obstante, si bien dicha cifra seguía siendo relativamente baja en comparación con 
otras regiones del país, colocándola en el lugar $2 \mathrm{I}$ en número de casos acumulados a nivel nacional, reflejaba, a su vez, un incremento del II $3.6 \%$ de contagios con respecto a la última semana del mes anterior, esto demostraba la velocidad con la que se propagaron los contagios.

A pesar de ello, no existe la certeza de que hayan contagios entre los trabajadores de Nissan o de alguna empresa de autopartes en el estado de Aguascalientes.

\section{Guanajuato}

El Estado de Guanajuato es una de las entidades con el mayor número de plantas para la fabricación de vehículos ligeros con un total de 4, las cuales corresponden a las empresas Volkswagen, General Motors, Honda y Mazda, que se encargaban, hasta diciembre del 2019, de producir de manera conjunta el $49.8 \%$ de los vehículos producidos a nivel nacional. A estas empresas se suman 420 de autopartes y otras 2 mil que corresponden al sector de servicios y comercio, ligadas directa e indirectamente a esta industria, empleando a 93 mil personas en total; por lo que la industria automovilística es la de mayor crecimiento del estado, aportando el 17\% del PIB de la entidad (Gobierno del estado de Guanajauto, 2018:70).

La empresa estadounidense General Motors, es la que tiene el peso más importante en este Estado, debido a que se encarga del $26 \%$ de la producción de vehículos y, en el mercado interno, representaba el I8.3\% de las ventas totales a nivel nacional, por debajo de Nissan; en cuanto a las exportaciones, la General Motors se encargaba de enviar la principal carga de vehículos a los distintos mercados extranjeros con el $21.7 \%$ de los autos producidos nacionalmente. Para ello, empleaba un total de 19 mil personas de forma directa.

No obstante, la desactivación temporal de la industria por la pandemia del coronavirus, provocó que la producción de esta empresa se redujera a cero; de igual forma, sus ventas en el mercado interno cayeron $65.4 \%$ en comparación con el mes de marzo y sus exportaciones hicieron lo propio con un $92.5 \%$.

Al igual que en el caso de Aguascalientes, la industria automotriz guanajuatense retomó paulatinamente sus operaciones a partir del $18 \mathrm{de}$ mayo, cuyo panorama de contagios por coronavirus era relativamente bajo, en comparación con otros estados del país, con un total de I,030 casos y con 86 fallecidos. Sin embargo, una vez que se inicia la nueva normalidad, en el estado había 2,278 personas contagiadas y 135 fallecidas, lo que representó un incremento del $121 \%$ y $57 \%$ en tan solo dos semanas respectivamente. Lo cual, colocaba a esta entidad en el lugar I 3 en número de casos a nivel nacional, donde anteriormente ocupaba el lugar 20. 
Fue por ello que un sector de los empleados de la General Motors se negó a regresar a trabajar, debido a que no se contaban con las condiciones necesarias dentro de las instalaciones. En el caso de Silao, donde se encuentra la planta de General Motors y en la que trabajan alrededor de 6,500 personas, era el sexto municipio con mayor número de contagios, de los 46 que conforman al estado, con un total de 56 casos y 4 fallecidos. Además de que mucha gente de Guanajuato, Irapuato y Salamanca, municipios con alto nivel de contagios, se trasladaba a Silao para trabajar en la planta de G.M.

Para estos momentos, existía un protocolo de seguridad sanitaria elaborado por el gobierno del estado, conforme a los lineamientos establecidos por las autoridades federales correspondientes, Ilamado Guía para la Reincorporación a los Centros de Trabajo ante el Covid-19, realizado por la Secretaría de Salud del estado de Guanajuato (2020), en el cual se enunciaba una serie de lineamientos generales con aspectos como organización, capacitación y medidas de prevención para conservar la seguridad sanitaria en los espacios de las plantas.

Para finales del mes de junio, el Movimiento Nacional Contra la Precarización Laboral y los Despidos, dieron a conocer que 7 trabajadores de la General Motors dieron positivo a la Covid- 19; un mes después, la cifra se elevó a 25, de los cuales 7 fallecieron, según la Organización Generando Movimiento (Ávila, 2020).

Durante este mismo periodo, mil 350 trabajadores perdieron su trabajo dentro de esta industria en Guanajuato, según el Sindicato de Trabajadores de la Industria Metal Mecánica Automotriz (Sitimm).

\section{A MANERA DE CONCLUSIÓN}

El escenario excepcional derivado de la pandemia de coronavirus a escala global, estableció una serie de condiciones adversas para la industria automotriz nacional, sobre todo, durante el primer bimestre de esta emergencia: la parálisis de esta industria derrumbó la producción total del país un 91.5\% de marzo a mayo, y las exportaciones $94.7 \%$; por lo que las ventas de vehículos decayeron $52 \%$.

Ante este escenario nada alentador y un tanto previsible, el gobierno federal dejó a un lado las recomendaciones, mayoritariamente de carácter económico, hechas por los representantes de la industria automotriz para afrontar la emergencia sanitaria y optó únicamente por reactivarla de forma paulatina a partir de categorizarla como una actividad esencial.

Esta definición significó el perfeccionamiento de las medidas de seguridad sanitaria en los centros de trabajo expuesto por las autoridades federales, a las que los diferentes estados homologaron sus protocolos de sanidad y a las que tuvieron que apegarse las grandes ensambladoras, como condición para que pudieran reactivar sus operaciones. 
Ahora bien, es indiscutible la necesidad de la implementación de medidas sanitarias ante el alarmante escenario nacional, en el que el número de contagios iba a la alza como en los casos de Guanajuato y, sobre todo, de Puebla, donde se consideraba la idea, todavía a finales de junio, de suspender por segunda vez las operaciones de su industria automovilista para contener la propagación de los contagios por coronavirus y, así, proteger a la mayor cantidad de trabajadores posibles; sin embargo, no es menos cierto que debió darse la misma prioridad a la cobertura de las necesidades económicas de la mayoría de los trabajadores de esta industria y de los diferentes subsectores, quienes se vieron duramente afectados y necesitaron un aliciente económico, que nunca llegó, para afrontar dicho escenario.

Por más que la mayoría de las empresas pudieron haber cumplido con la implementación de medidas sanitarias en el interior de sus instalaciones, no pudieron hacer mucho para mantener a sus trabajadores durante la suspensión de sus operaciones, sin activos y sin el apoyo amplio de los gobiernos, quienes únicamente implementaron medidas sanitarias.

Las grandes ensambladoras cuidaron en todo momento sus intereses económicos, por lo que tuvieron que reacomodar sus nóminas para ajustar sus finanzas, aunque ello implicara incurrir a la ilegalidad (reduciéndoles el salario a sus trabajadores o despidiendo una cantidad significativa de estos), de tal manera que el trabajador terminó totalmente indefenso en términos económicos.

Hasta ahora, ha costado el despido de más de 24 mil trabajadores directos en todo el territorio del país, de los cuales, el I5\% pertenecen a Puebla, Aguascalientes y Guanajuato, estados de amplia actividad automotriz. El efecto se propagó por toda la cadena productiva de empresas de autopartes y más allá de ésta, afectando varias actividades relacionadas con el sector terciario.

En ese sentido, se puede afirmar que no fue suficiente que el gobierno decidiera no declarar la contingencia sanitaria, para no facilitar el despido de los trabajadores y recortar los salarios.

Con esto nos referimos a que las medidas sanitarias fueron tardías e insuficientes para proteger a la industria automotriz y, sobre todo, a sus trabajadores durante la pandemia en nuestro país, en tanto que no hubo medidas económicas (como seguro de desempleo, subsidios, etc.) de gran espectro y focalizadas a esta industria por parte del gobierno federal; de esta forma, pudo haberse reducido el número de despidos y sobre todo, evitar exponer la salud de los trabajadores, permitiéndoles respetar la cuarentena con mayor certidumbre económica.

Sin embargo, también debemos tener en cuenta que en ningún país con un sector importante de industria automotriz y que representan economías más sólidas que la mexicana, como Estados Unidos, Alemania, Italia China y Japón, se pudo evitar, durante este mismo periodo, los masivos despidos de los trabajadores de las plantas automotrices, así como sostener el dinamismo de la producción de vehículos en sus respectivos territorios. 


\section{BIBLIOGRAFÍA}

Aguilar García, Javier (1982). La política sindical en México: Industria del automóvil. Ed. Era, México, colección “Problemas de México”, p. 195.

Aguilar García, Javier (1978) "El sindicalismo del sector automotriz 19691976" en Cuadernos Políticos. Ed. Era, No. 16, abril-junio de 1978, pp. 44 a 64.

Aguilar García Javier (1988). Los sindicatos nacionales en el México contemporáneo, Vol. 3 : "Industrias dinámicas”. Ed. G.V., México, p. 365.

Asociación Mexicana de Distribuidores de Automotores (2017). Diálogo con la Industria Automotriz. 2018-2024. AMDA. Consultado en agosto del 2020. En línea https://www.amda.mx/wp-content/uploads/asociaciones_2018-2024_180724.pdf.

Ávila, Alfonsina (2020). Habría hasta 25 casos de Covid-19 entre trabajadores de GM; siete ya fallecieron. Consultado en agosto del 2020. En línea https:// zonafranca.mx/politica-sociedad/salud/denuncian-hasta-25-casos-decovid-19-entre-trabajadores-de-gm-en-silao-siete-ya-fallecieron/

Cámara de Industria y Comercio Argentino Alemana (2020). Impacto de Covid-19 en el sector automotriz. Consultado en agosto del 2020. En línea https://www.ahkargentina.com.ar/actualidad/news-details/ impacto-de-covid-19-en-el-sector-automotriz

Cantera, Sara (2020). Virus desbiela a toda la industria automotriz. El Universal. Consultado en agosto del 2020. En línea https://www.eluniversal.com.mx/cartera/virus-desbiela-toda-la-industria-automotriz

Clúster Industrial (2020a). AIMA nombra a José Zozaya como presidente ejecutivo. Revista Clúster Industrial. Consultado en agosto del 2020. En línea https://www.clusterindustrial.com.mx/noticia-detalle.php?noticia=2487

Clúster Industrial (2020b). COVID-19 y su impacto en la industria automotriz de México. Revista Clúster Industrial. Consultado en agosto del 2020. En línea https://www.clusterindustrial.com.mx/noticia-detalle.php?noticia=2108

DW.COM (2020). Desempleo en EE.UU. se dispara del 4.4\% al 14.5 por ciento. Consultado en agosto del 2020. En línea https://www.dw.com/es/ desempleo-en-eeuu-se-dispara-del-44-al-147-por-ciento/a-53374394

Forbes (2020). Renault podría desaparecer por crisis de coronavirus, advierte Francia. Revista Forbes. Consultado en agosto del 2020. En línea https:// www.forbes.com.mx/mundo-renault-puede-desaparecer-advierte-francia/

Gobierno del Estado De Guanajuato (2018). Plan Estatal de Desarrollo Guanajuato 2040. Instituto de Planeación, Estadística y Geografía del estado de Guanajuato. Consultado en agosto del 2020. En línea http:// plangto2040.iplaneg.net

Hernández, Miguel (2020). IMEF prevé recuperación en Puebla por el coronavirus en el año 2022. El Economista. Consultado en agosto del 2020. En línea https://www.eleconomista.com.mx/estados/ 
IMEF-preve-recuperacion-en-Puebla-por-el-coronavirus-en-elano-2022-20200625-0153.html

Infobae (2020). Cómo el coronavirus puso de rodillas a la industria automotriz mundial. Infobae. Consultado en agosto del 2020. En línea https://www.infobae.com/autos/2020/03/15/como-el-coronavirus-puso-de-rodillas-a-la-industria-automotriz-mundial/

INEGI (2020a). Reporte mensual. Registro administrativo de la industria automotriz de vehículos ligeros. Consultado en agosto de 2020. En línea https://www.inegi.org.mx/contenidos/saladeprensa/notasinformativas/2020/rm_raiavl/rm_raiavl2020_04.pdf

INEGI (2018). Conociendo la Industria Automotriz. Consultado en agosto del 2020. En línea https://www.inegi.org.mx/contenidos/saladeprensa/ boletines/2018/

Instituto de Servicios de Salud del Estado de Aguascalientes (2020). Protocolo en materia de protección contra riesgos sanitarios covid-19. Industria automotriz. ISSEA. Consultado en agosto del 2020. En línea https://www.aguascalientes.gob.mx/sedec/pdf/mayo2020/PROTOCOLO_PROTECCION.pdf.

Industria Nacional de Autopartes (2019). Perspectivas de la industria Terminal a Nivel Mundial. INA. Consultado en agosto del 2020. En línea http://icpserver.com.mx/documents/videos/la-industria-de-autopartesde-mexico-ante-el-covid-19.pdf.

Juárez, Pilar y López, José (2020) Industria automotriz perderá uno de cada 5 empleos por coronavirus. Milenio. Consultado en agosto del 2020. En línea https://www.milenio.com/negocios/ coronavirus-industria-automotriz-perdera-5-empleos.

Meléndez, Evelia (2020). En riesgo 18 mil empleos del sector automotriz por COVID-19. Puebla online. Consultado en agosto del 2020. En línea https://pueblaonline.com.mx/2019/portal/movil/index.php/estado/ item/97002-en-riesgo-18-mil-empleos-del-sector-automotriz-por-covid-19\#.Xz7qrH623IU.

Mendoza, Viridiana (2019). El futuro de la industria automotriz es cuesta arriba. Revista Forbes. Consultado en agosto 2020. En línea https://www.forbes. com.mx/el-futuro-de-la-industria-automotriz-es-cuesta-arriba/

Morillón, Maribel (2020). Van más de 2 mil despidos en Puebla por causa del Covid-19. Consultado en agosto del 2020. En Línea https://www.e-consulta.com/nota/2020-04-01/economia/ van-mas-de-2-mil-despedidos-en-puebla-por-causa-del-covid-19.

Portal Automotriz (2020). El cierre de fábricas ya afecta a 1.1 millones de empleos del sector automotriz en Europa. Consultado en agosto 2020. En línea https://www.portalautomotriz.com/noticias/automotriz/el-cierre-de-fabricas-ya-afecta-a-11-millones-de-empleos-del-sector-automotriz. 
Ramos, Mario (2020a). Peligra empleo en sector automotriz por coronavirus. El Sol de México. Consultado en agosto del 2020. En línea https://www. elsoldemexico.com.mx/finanzas/peligra-empleo-en-sector-automotrizpor-coronavirus-5001095.html.

Ramos, Mario (2020b). Reinicia despidos de Nissan en México. El Sol de México. Consultado en agosto del 2020. En línea https://www.elsoldemexico.com.mx/republica/sociedad/reinician-despidos-de-nissan-enmexico-5323965.html.

Rodríguez, Ivet (2020). Expansión. Consultado en agosto del 2020. En línea https://expansion.mx/empresas/2020/06/10/ el-desempleo-acecha-a-las-plantas-de-autopartes-en-mexico.

Sánchez, Axel (2020a). En el sector automotor se despidieron a 823 personas al día durante abril. El Financiero. Consultado en agosto del 2020. En línea https://www.elfinanciero.com.mx/empresas/ sector-automotriz-despide-a-823-personas-diarias-durante-abril

Sánchez, Axel (2020b), Reapertura de la industria automotriz a nivel nacional se retrasaría por "luz roja" en Puebla. El Financiero. Consultado en agosto del 2020. En línea https://www.elfinanciero. com.mx/empresas/puebla-retrasaria-reapertura-de-la-industria-automotriz-y-autopartes.

Secretaría de Salud (2020). Lineamientos Técnicos para la Reapertura de las Actividades Económicas. Secretaría de Salud, México. Consultado en agosto del 2020. En Línea http://nuevanormalidad.gob.mx/files/ Acuerdo_Salud_290520_VES-1.pdf?

Secretaría de Salud del Estado de Guanajuato (2020). Guía para la Reincorporación a los Centros de Trabajo ante el Covid-19. En línea https://coronavirus.guanajuato.gob.mx/pdf/FOLLETO-CORONAVIRUS_ REGRESO-A-TRABAJO.pdf?fbclid=IwAR2h5-pYUxLXny5dhhVY_ NyMLg510pc2xBV_ursEEiAAMudm-CzAtUnZpFM . Consultado en agosto del 2020.

Secretaría del Trabajo y Previsión Social (2020). COMUNICADO Número 014/2020 El 87\% de empresas inspeccionadas cumple con las medidas sanitarias ante el COVID-19. STPS. Consultado en agosto del 2020. En línea https://www.gob.mx/stps/prensa/comunicado-numero-014-2020.

Télma.Com (2020) El desempleo en la eurozona subió al 7.3\% en abril por la pandemia. Consultado en agosto del 2020. En línea https://www.telam. com.ar/notas/202006/471567-desempleo-europa-coronavirus.html

Zepeda, Genaro (2020) Industria Automotriz reinicia actividades productivas en Puebla. Consultado en agosto del 2020. En línea https://www.unotv. com/noticias/estados/puebla/detalle/en-puebla-industria-automotrizreinicia-actividades-productivas-093573/. 